\title{
Heme Oxygenase 1 and 2 Differentially Regulate Glucose Metabolism and Adipose Tissue Mitochondrial Respiration: Implications for Metabolic Dysregulation
}

\author{
Hongwei Yao ${ }^{1, \dagger}$, Abigail L. Peterson ${ }^{1,+}{ }^{,} \mathrm{Jie} \mathrm{Li}^{2}$, Haiyan $\mathrm{Xu}^{2}$ and Phyllis A. Dennery ${ }^{1,3, *}$ \\ 1 Department of Molecular Biology, Cell Biology \& Biochemistry, Division of Biology and Medicine, Brown \\ University, Providence, RI 02860, USA; hongwei_yao@brown.edu (H.Y.); \\ abigail_peterson@brown.edu (A.L.P.) \\ 2 Department of Epidemiology, Brown University, Providence, RI 02860, USA; jie_li@brown.edu (J.L.); \\ Haiyan_Xu@brown.edu (H.X.) \\ 3 Department of Pediatrics, Warren Alpert Medical School of Brown University, Providence, RI 02860, USA \\ * Correspondence: phyllis_dennery@brown.edu; Tel.: +1-401-444-5648 \\ + These authors contributed equally to this work.
}

Received: 2 September 2020; Accepted: 24 September 2020; Published: 27 September 2020

check for updates

\begin{abstract}
Heme oxygenase (HO) consists of inducible (HO-1) and constitutive (HO-2) isoforms that are encoded by Hmox 1 and Hmox 2 genes, respectively. As an anti-inflammatory and antioxidant molecule, HO participates in the development of metabolic diseases. Whether Hmox deficiency causes metabolic abnormalities under basal conditions remains unclear. We hypothesized that HO-1 and HO-2 differentially affect global and adipose tissue metabolism. To test this hypothesis, we determined insulin sensitivity, glucose tolerance, energy expenditure, and respiratory exchange ratio in global $\mathrm{Hmox}^{--}$and Hmox $2^{--}$mice. Body weight was reduced in female but not male Hmox $1^{--}$ and $H$ mox $2^{--}$mice. Reduced insulin sensitivity and physical activity were observed in $\mathrm{Hmox}^{-{ }^{-}}$but not $\mathrm{Hmox}_{2}{ }^{--}$mice. Deletion of either Hmox1 or Hmox 2 had no effects on glucose tolerance, energy expenditure or respiratory exchange ratio. Mitochondrial respiration was unchanged in gonadal fat pads (white adipose tissue, WAT) of $H m o x 1^{-1}$ mice. Hmox2 deletion increased proton leak and glycolysis in gonadal, but not interscapular fat tissues (brown adipose tissue, BAT). Uncoupling protein and Hmox1 genes were unchanged in gonadal fat pads of Hmox $2^{--}$mice. Conclusively, HO-1 maintains insulin sensitivity, while HO-2 represses glycolysis and proton leak in the WAT under basal condition. This suggests that HO-1 and HO-2 differentially modulate metabolism, which may impact the metabolic syndrome.
\end{abstract}

Keywords: heme oxygenase; insulin sensitivity; glucose tolerance; energy expenditure; white adipose tissue; brown adipose tissue

\section{Introduction}

Heme oxygenase $(\mathrm{HO})$ consists of inducible (HO-1) and constitutive (HO-2) isoforms that are encoded by Hmox 1 and Hmox 2 genes, respectively. HO- 1 is ubiquitously expressed in many organs, including the lung, heart, skeletal muscle, kidney, and spleen. It is also expressed in metabolic organs, including the liver and white adipose tissue [1]. HO-2 is highly expressed in the testis and brain [2,3]. As an Nrf2-dependent gene, HO-1 protein can modulate its own gene expression in a feed forward transcriptional manner [4]. In addition, HO-1 can interact with and modulate Nrf2 activation, setting an adaptive reprogramming that enhances antioxidant defenses [5]. Although $\mathrm{HO}-2$ is constitutively 
expressed, the Hmox2 gene can also be regulated by glucocorticoids through the glucocorticoid responsive element in rat testis [2]. HO catalyzes the degradation of heme yielding cytoprotective products, including bilirubin, ferritin, and carbon monoxide. Heme, an iron-protoporphyrin IX, is an essential co-factor involved in multiple biological processes, including oxygen transport and storage, electron transfer, drug and steroid metabolism, and signal transduction. However, excess free-heme is highly toxic due to its ability to promote oxidative stress. HO products have been shown to suppress oxidative stress and inflammatory responses. Therefore, HO-1 is considered as a classical component of stress response to a variety of chemical and physical stimuli, and $\mathrm{HO}$ functions as a cytoprotective molecule [6,7].

Accumulating evidence shows that $\mathrm{HO}$ by-products also participate in glucose metabolism as well as in the development of metabolic syndrome and disorders. This syndrome is characterized by obesity, hyperglycemia, dyslipidemia, and insulin resistance concomitant with other abnormalities, including hypertension. A sedentary lifestyle, physical inactivity, and poor eating habits are aggravating factors $[8,9]$. For instance, serum bilirubin levels are lower in overweight asymptomatic middle-aged adults [10]. Elevated ferritin for iron stores is positively associated with the prevalence of metabolic syndrome and with insulin resistance [11]. Carbon monoxide induces metabolic switch in adipocytes and reduces insulin resistance in obese mice [12]. Administration of hemin, an HO-1 inducer, protects against streptozotocin-induced increase in blood glucose in rats [13]. This suggests that HO may play an important role in modulating glucose and energy metabolism. In fact, $\mathrm{HO}$ activity is increased after exercise in healthy volunteers [14], but is reduced in obese mice compared with age-matched lean mice [15]. Pharmacological administration of the HO-1 inducer cobalt protoporphyrin reduces weight gain, visceral and subcutaneous fat content, and insulin levels but improves insulin sensitivity and glucose tolerance in obese mice [15]. This is associated with increased adiponectin and reduced inflammatory responses. In contrast, inhibition of $\mathrm{HO}$ activity by stannous mesoporphyrin decreases adiponectin and increases secretion of inflammatory cytokines in obese mice [15]. Nevertheless, whether $\mathrm{HO}$ deficiency causes metabolic abnormalities under basal conditions remains unclear.

We hypothesized that HO-1 and HO-2 differentially affect global and adipose tissue metabolism. To test this hypothesis, we first determined insulin sensitivity, glucose tolerance, energy expenditure, and respiratory exchange ratio in $\operatorname{Hmox} 1$ knockout $\left(\operatorname{Hmox}_{1}{ }^{--}\right)$and $H m o x 2^{---}$mice as well as mitochondrial respiration and glycolysis in white adipose tissue (WAT). Metabolic dysregulation is associated with low physical activity and leads to cognitive decline $[16,17]$. We, therefore, also evaluated physical activity and motor coordination in these knockout mice compared to their wild-type (WT) littermates.

\section{Results}

\subsection{Body Weight Was Reduced in Female Hmox $1^{--}$and Hmox $2^{--}$Mice Compared to Their Female WT Littermates}

We assessed body weight of Hmox $1^{--}$and Hmox2 $2^{--}$mice as well as their WT littermates at 4-5 months of age to determine whether the mice had early evidence of obesity. In agreement with a previous study [18], body weight was not altered in $\mathrm{Hmox}^{--}$mice when data were mixed from male and female mice. We then compared body weight in male and female knockout mice separately. There were no differences in body weight of male Hmox $1^{--}$and Hmox $2^{--}$mice compared to their male WT littermates, although sample sizes were small in certain groups (Figure 1A). However, body weight was reduced in both female $\mathrm{Hmox}_{1}{ }^{--}$and Hmox $2^{--}$mice compared to their female WT littermates (Figure 1B). Although there were no differences in age among these groups (Yao H, Peterson AL, Dennery PA. Brown University, Providence, RI. Heme oxygenase/metabolism. 2020), Hmox $2^{-/-}$ mice grew faster than their WT littermates at 4-5 months old (Figure 1A). These results demonstrate that deletion of Hmox 1 and Hmox 2 affects body weight in a gender-specific manner but does not suggest obesity. 

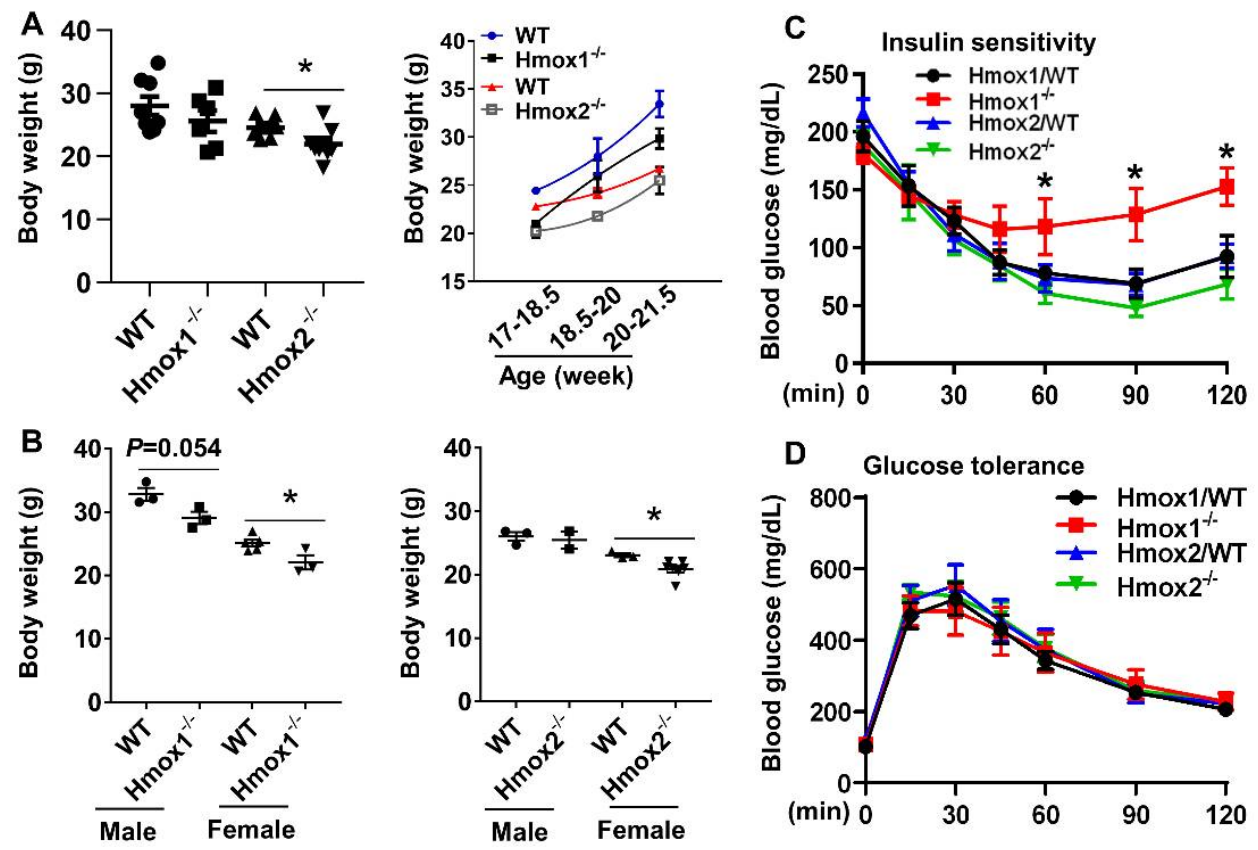

Figure 1. Insulin sensitivity was reduced in $H m o x 1^{-/-}$but not in $H m o x 2^{-/-}$mice. Hmox $1^{-/-}, H m o x 2^{-/-}$ mice and their wild-type (WT) littermates (4-5 months old) were used for detecting insulin sensitivity and glucose tolerance. (A,B) Body weight of $H m o x 1^{-/-}, H m o x 2^{-/-}$mice and their WT littermates were assessed. (A) Left panel denotes body weight of mixed male and female mice, while right panel denotes the changes in body weight with different ages. (C) Insulin (1.25 U/kg for females, $2 \mathrm{U} / \mathrm{kg}$ for males) was intraperitoneally injected, and blood glucose was measured at 0, 15, 30, 45, 60, 90, and $120 \mathrm{~min}$ post injection. (D) Glucose $(2 \mathrm{~g} / \mathrm{kg})$ was intraperitoneally injected, and blood glucose was measured at $0,15,30,45,60,90$, and 120 min post injection. Data are expressed as mean \pm SEM. $n=7-9 .{ }^{*} p<0.05$ vs. corresponding WT littermates.

\subsection{Insulin Sensitivity Was Reduced in Hmox $1^{--}$But Not in Hmox $2^{--}$Mice}

We determined whether deletion of Hmox1 and Hmox2 alters insulin sensitivity by injecting insulin and measuring blood glucose levels within $2 \mathrm{~h}$ post injection. As shown in Figure 1C, as expected, in WT mice, blood glucose gradually decreased after insulin injection, whereas it remained elevated in $\mathrm{Hmoxx}^{--}$mice, which denotes loss of insulin sensitivity. In contrast, there were no differences in insulin sensitivity between $\mathrm{Hmox}_{2}{ }^{--}$and WT littermates. We then intraperitoneally injected glucose and measured blood glucose levels for a $2 \mathrm{~h}$ period post injection to assess glucose tolerance. As shown in Figure 1D, there were no changes in glucose tolerance among Hmox $1^{--}$and Hmox $2^{--}$mice compared to their WT littermates. No sex differences in insulin sensitivity or glucose tolerance were observed in both Hmox $1^{--}$and Hmox2 $2^{--}$mice compared to their WT littermates (Yao H, Peterson AL, Dennery PA. Brown University, Providence, RI. Heme oxygenase/metabolism. 2020). These results demonstrate that Hmox1 deletion decreases insulin sensitivity but does not affect glucose tolerance under basal conditions. As for Hmox2, its deletion has no effect on glucose tolerance or insulin sensitivity.

\subsection{Deletion of Hmox1 But Not Hmox2 Reduced Times for Active Behaviors}

To determine the effects of $\mathrm{HO}$ on physical activity, we utilized continuous home cage video monitoring to measure times spent on resting and active behaviors $[19,20]$. As shown in Figure $2 A, B$, compared to WT littermates, $H$ mox $1^{-/-}$mice had reduced times spent on active behaviors but not for resting. In the Hmox $2^{--}$, there were no changes in times spent on resting or active behaviors compared to WT littermates (Figure 2A,B). No sex differences in physical activity were observed in both Hmox $\mathrm{I}^{--}$ and Hmox $2^{--}$mice compared to their WT littermates (Figure $2 \mathrm{C}, \mathrm{D}$ ). These results demonstrate that times of active behaviors are reduced in $\mathrm{Hmox}^{-{ }^{--}}$but not $H m o x 2^{-/-}$mice. 

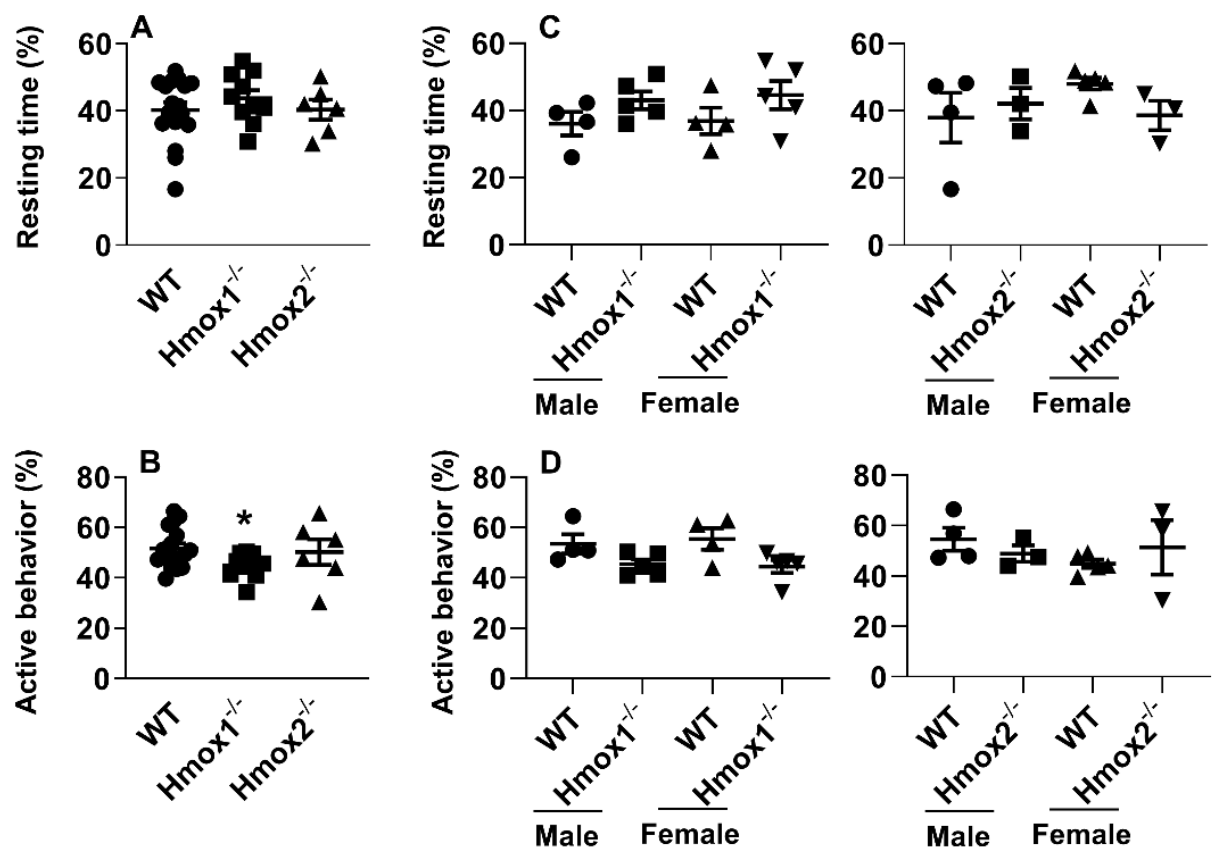

Figure 2. Physical activity was reduced in $H \operatorname{mox} 1^{-/}$but not in $H m o x 2^{-/}$mice. Physical activity was assessed in $\mathrm{Hmox}_{1} \mathrm{H}^{-}$, Hmox $2^{-/}$mice and their WT littermates (4-5 months old) using continuous home cage video monitoring. (A,C) Percentage of resting time was calculated. (B,D) The sum of walking, hanging, grooming, and rearing was recorded as active behavior. Data are expressed as mean \pm SEM. $n=6-10 .{ }^{*} p<0.05$ vs. corresponding WT group.

\subsection{Motor Coordination Was Not Altered in Hmox1 $1^{--}$or Hmox2 $2^{--}$Mice}

The rotarod test is commonly used to assess motor coordination and balance in rodents [21]. High fat-feeding significantly accelerates decline in rotarod performance in mice [22]. As shown in Figure 3, there were no changes in the motor coordination or balance in terms of time before dropping from the rod or the maximal speed attained between Hmox $1^{--}$mice and WT littermates. There were no sex differences in physical activity between $\mathrm{Hmox}^{-{ }^{--}}$mice and WT littermates (Figure 3). Similarly, there were no significant differences in motor coordination between Hmox $2^{--}$and WT mice at 4-6 months old [23]. These results indicate that $\mathrm{HO}$ deficiency alone has no effects on motor coordination.

A Acceleration

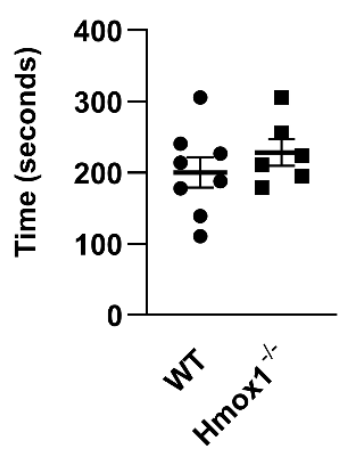

Acceleration

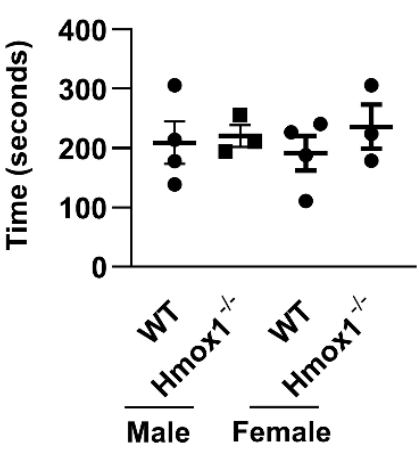

B

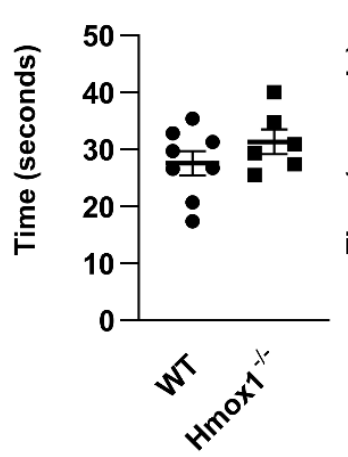

Maximal RPM

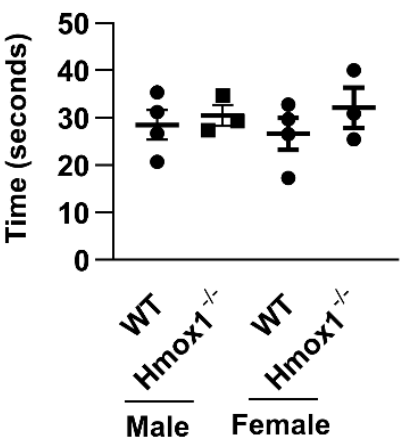

Figure 3. No changes in motor coordination between Hmox $1^{--}$mice and WT littermates. Motor coordination was measured using the rotarod test in $H$ mox $1^{--}$mice and WT littermates (4-5 months old). Riding time was recorded when the rotarod was hold accelerated (acceleration, A) or at the maximal speed (B). Data are expressed as mean \pm SEM. $n=6-8$. 


\subsection{No Changes in Energy Metabolism or Respiratory Exchange Ratio in Either Hmox1 or Hmox2 knockout Mice}

Dysregulated energy metabolism is essential to the etiopathogenesis of metabolic syndrome $[16,24,25]$. Hence, we employed a metabolic chamber to evaluate energy expenditure and respiratory exchange ratio in both $\mathrm{Hmox} \mathrm{1}^{--}$and $\mathrm{Hmox}_{2}{ }^{--}$mice. As shown in Figure 4, energy expenditure and respiratory exchange ratio were unchanged in either $H m o x 1^{--}$or $H m o x 2^{--}$mice compared to their WT littermates. There were no sex differences in energy expenditure or respiratory exchange ratio in both $\mathrm{Hmox}_{1} \mathrm{H}^{--}$and Hmox $2^{--}$mice compared to their WT littermates (Figure 4). These results suggest that $\mathrm{HO}$ does not affect energy metabolism in mice.
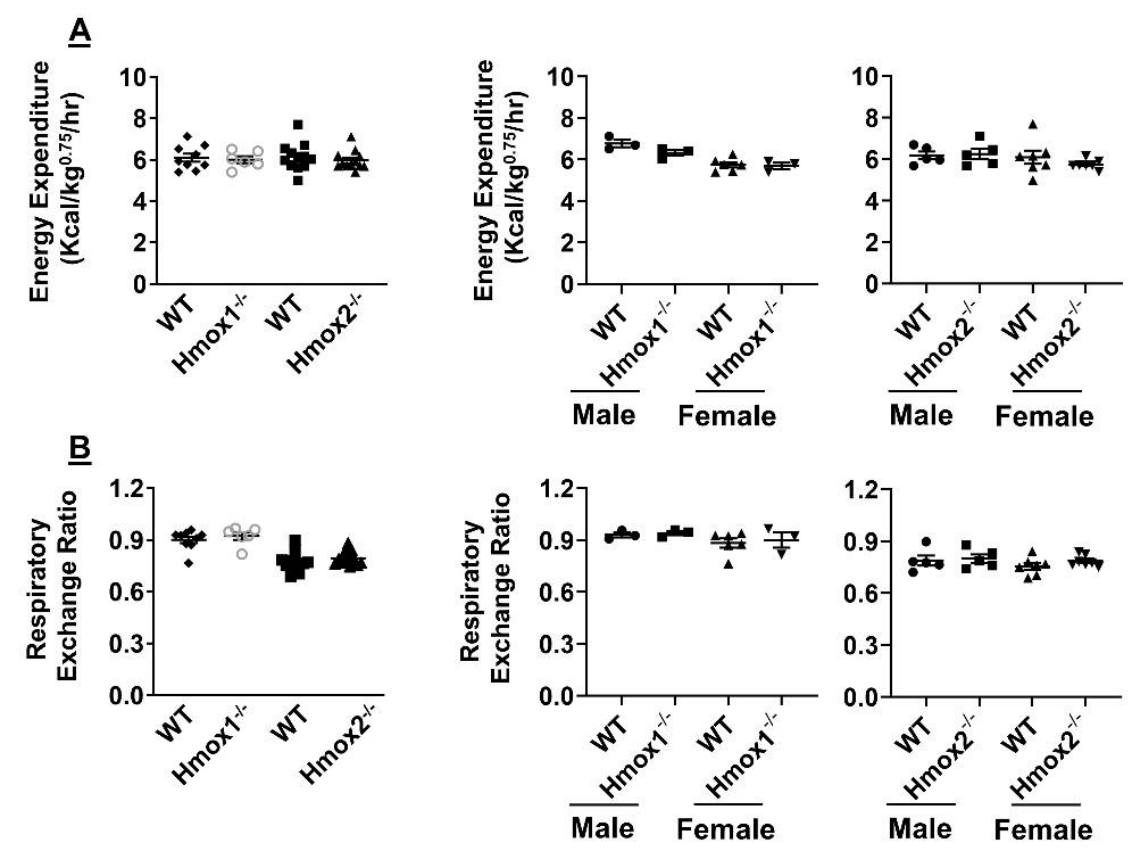

Figure 4. No changes in energy expenditure or respiratory exchange ratio in Hmox $1^{--}$and Hmox $2^{--}$ mice. Energy expenditure and respiratory exchange ratio was measured using the metabolic chamber in Hmox $1^{--}, H m o x 2^{--}$mice and their WT littermates (4-5 months old). Energy expenditure (A) and respiratory exchange ratio $(B)$ were calculated. Data are expressed as mean \pm SEM. $n=6-12$.

2.6. No Changes in Mitochondrial Respiration in WAT of Hmox1 $1^{--}$Mice, While Hmox2 Deletion Increased Proton Leak and Glycolysis in WAT

The WAT plays an essential role in regulating systemic energy homeostasis [26]. The main WAT pads in the mouse are the inguinal and gonadal regions, with the latter being the most frequently utilized in experiments $[27,28]$. We, thus, normalized the weight of gonadal fat pads to body weight. As shown in Figure 5A, there were no differences in the ratio of WAT/body weight in both Hmox1 ${ }^{--}$ and Hmox $2^{--}$mice compared to their corresponding WT littermates. We then determined WAT mitochondrial oxidative phosphorylation using an XF24 Seahorse Analyzer in the Hmox $1^{--}$and Hmox $2^{--}$ mice. As shown in Figure 5B, mitochondrial respiration, including basal respiration, proton leak and spare respiratory capacity, was unchanged in gonadal fat pads of $\mathrm{Hmox}_{1}{ }^{--}$mice compared to WT littermates. Levels of proton leak were increased in gonadal fat pads of Hmox $2^{--}$mice compared to WT littermates. There were no changes in basal respiration or spare respiratory capacity of WAT between Hmox $2^{--}$mice and WT littermates (Figure 5B). The results demonstrate that Hmox2 deletion increases proton leak to dissipate energy as heat or reduce ATP synthesis. 
A

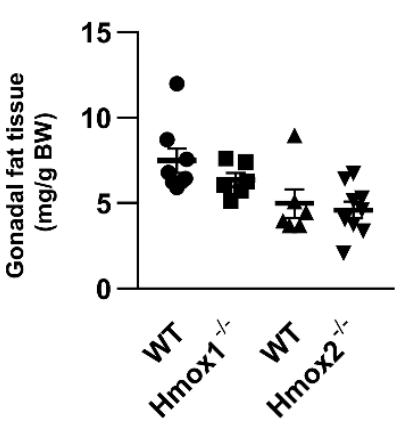

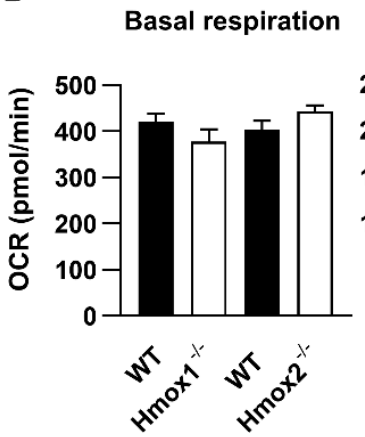

Proton Leak

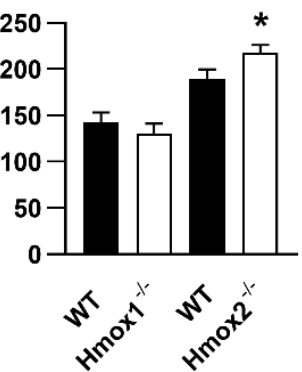

Spare Respiratory

Capacity \%

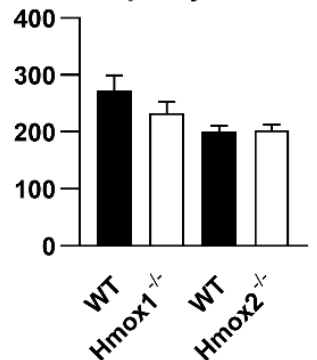

Figure 5. Mitochondrial respiration in gonadal white adipose tissue (WAT) of Hmox1-- and $H m o x 2^{-/-}$ mice. (A) Gonadal fat pads were weighted in $\mathrm{Hmox}_{1}{ }^{-}, H$ mox $2^{--}$mice and their WT littermates (4-5 months old). (B) Mitochondrial oxidative phosphorylation was measured using a Seahorse Analyzer in gonadal fat pads from $\operatorname{Hmox}_{1}{ }^{--}, \operatorname{Hmox} 2^{--}$mice and their WT littermates. Data are expressed as mean \pm SEM. $n=6-10 .{ }^{*} p<0.05$ vs. corresponding WT group.

Since proton leak was increased in WAT of $H m o x 2^{--}$mice, we also measured glycolysis in gonadal fat pads of these mice. Basal glycolysis and glycolysis were calculated as extracellular acidification (ECAR) before (basal) and after (glycolysis) glucose injection during the glycolysis stress test. As shown Figure 6A, basal glycolysis was increased in WAT from Hmox $2^{--}$mice compared to WT littermates. Brown adipose tissue (BAT) contains many more mitochondria than does the WAT. Thus, we also measured whether there were any changes in mitochondrial respiration in the interscapular fat pads of Hmox $2^{-/}$mice, which contain BAT. As shown in Figure 6B, basal respiration and proton leak were not changed in the BAT of Hmox $2^{-/}$mice compared to WT littermates. Altogether, Hmox1 deletion has no effect on mitochondrial respiration, while Hmox2 deletion increased proton leak and glycolysis in the WAT.
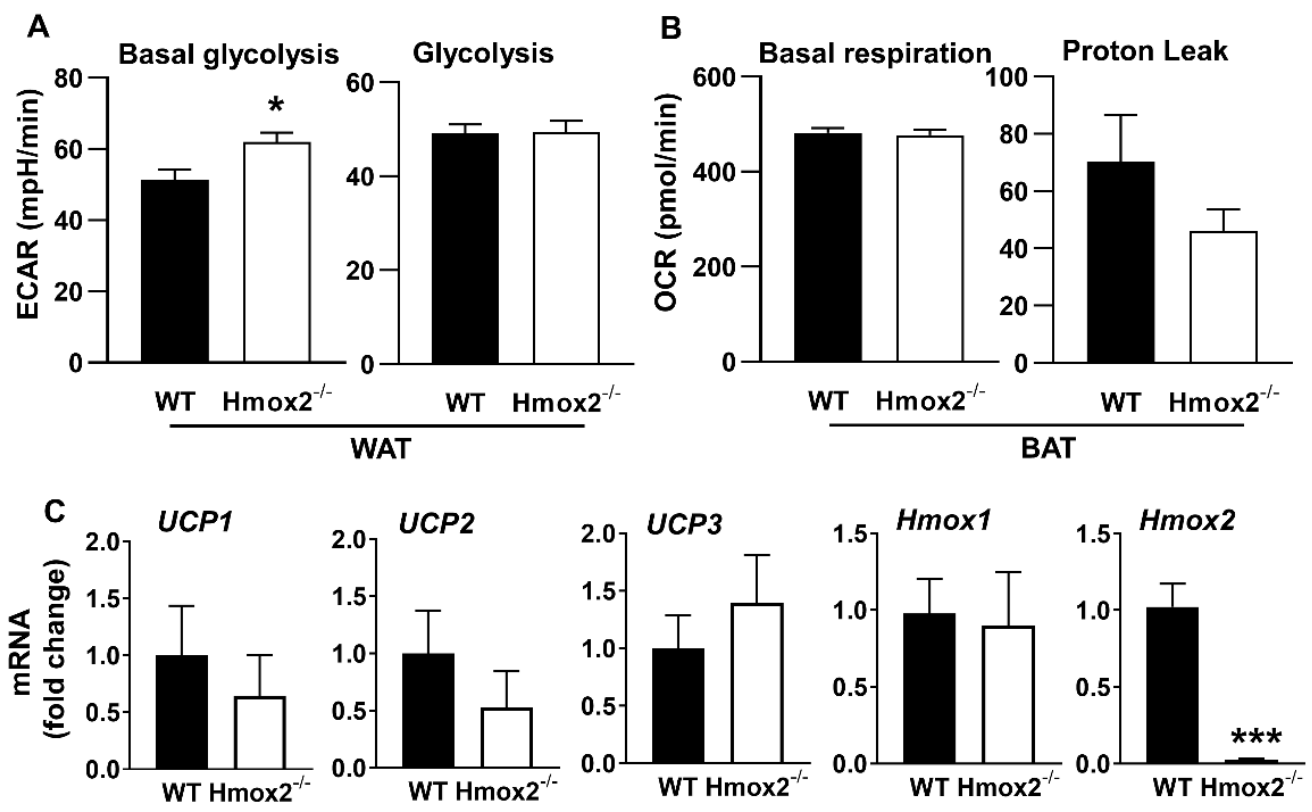

Figure 6. Glycolysis in gonadal WAT and mitochondrial respiration in interscapular brown adipose tissue (BAT) of Hmox $2^{--}$mice. Glycolysis (A) and mitochondrial oxidative phosphorylation (B) were measured using a Seahorse Analyzer in gonadal and interscapular fat pads, respectively, from Hmox $2^{--}$ mice and WT littermates. (C) Uncoupling protein (UCP)1, UCP2, UCP3, Hmox1, and Hmox2 gene expression were measured by qRT-PCR in gonadal WAT of WT and Hmox $2^{--}$mice. Data are expressed as mean \pm SEM. $n=5-7 .{ }^{*} p<0.05,{ }^{* * *} p<0.001$ vs. WT group. 


\subsection{No Changes in Uncoupling Protein (UCP) or Homx1 Genes in Gonadal Fat Pads of Hmox2-- Mice}

To determine whether increased proton leak in gonadal fat pads of $\mathrm{Hmox} 2^{--}$is associated with changes in UCP, we measured UCP1, UCP2 and UCP3 gene expression. As shown in Figure 6C, there were no changes in UCP1, UCP2 or UCP3 gene expression in gonadal fat pads of Hmox $2^{--}$mice compared to WT littermates. In addition, Hom $x 1$ gene expression was unchanged in gonadal fat pads of $\mathrm{Hmox}_{2} \mathrm{r}^{--}$mice compared to WT littermates (Figure 6C). These results suggest that there were no compensatory changes in Hmox1 gene in Hmox $2^{--}$mice, and Hmox2 deletion-mediated metabolic changes in gonadal fat pads are not associated with $U C P$ gene expression.

\section{Discussion}

HO has been implicated in the development of metabolic diseases, including obesity, diabetes, and hepatic steatosis $[1,29,30]$. Here we showed that body weight was reduced in both female Hmox $1^{--}$ and Hmox $2^{--}$mice. In addition, $\mathrm{Hmox}_{1} \mathrm{~T}^{--}$mice spontaneously developed insulin resistance and had reduced physical activity. This was not observed in Hmox2 knockout mice. Neither genotype had changes in energy expenditure or respiratory exchange compared to their WT littermates. Since both isoforms of $\mathrm{HO}$ catabolize the same enzymatic reaction, it is unlikely that the effect of Hmox1 deletion on insulin resistance is tied to heme metabolism.

HO-1 expression in visceral adipose tissue (WAT) negatively correlates with waist-to-hip ratio and insulin resistance in humans [31]. This is supported by a study showing that HO-1 levels are reduced in adipocytes isolated from visceral fat tissues of obese mice compared to lean mice [30]. Ablation of Hmox 1 in adipose tissue increases pro-inflammatory visceral fat and abrogates a beige-cell like phenotype, a comparable thermogenic potential to brown fat cells [32]. This is in contrast to our findings that global deletion of Hmox 1 had no effect on the weight of gonadal fat tissue (WAT). This suggests a fat type-specific role of HO-1. Additionally, overexpression of Hmox1 in adipose tissue does not protect against high fat diet-induced insulin resistance in mice [33], whereas in streptozotocin-induced diabetic rats, chronic induction of HO- 1 by hemin reduces hyperglycemia and improves glucose metabolism [13]. This may suggest that HO-1 is not instrumental in diet-induced insulin resistance but may play a larger role in a more severe model of diabetes. Interestingly, in an ageand body mass index-matched cohort, Hmox 1 expression and HO-1 protein were augmented in livers and visceral fat of insulin-resistant, compared to insulin-sensitive, obese patients [1]. This suggests that HO-1 drives meta-inflammation and insulin resistance. We noticed that the insulin activity was intact based on the normal glucose tolerance test and the early response upon insulin challenge (first $30 \mathrm{~min}$ ) in $\mathrm{Hmox}^{-1-}$ mice, compared to WT mice. In mice, conditional knockout of Hmox1 in hepatocytes or macrophages does not affect liver morphology, basal blood glucose, or glucose tolerance [1]. This is in agreement with our findings that global knockout of Hmox1 does not influence glucose tolerance. Insulin sensitivity can be improved by exercise and the latter has been shown to increase HO-1 activity $[14,34,35]$. Thus, reduced physical activity could have contributed to the reduced insulin sensitivity in $\mathrm{Hmox}_{\mathrm{N}} \mathrm{T}^{--}$mice in our experiments. The reduced late insulin response in $H m o x 1^{-1}$ mice could be induced by insulin antagonistic pathways in response to hypoglycemia such as hepatic gluconeogenesis, alterations in the hypothalamic-pituitary-adrenal axis and increased inflammatory cytokines [36,37]. We did not explore these possibilities here. Overall, the mechanisms underlying impaired insulin signals in $H m o x 1^{-1-}$ mice remain unclear, especially when paired with normal glucose tolerance.

HO-1 is considered as a potential biomarker in Alzheimer's disease and mild cognitive impairment [38]. Overexpression of Hmox1 causes cognitive decline by regulating tauopathy in mice [39]. In aging rats, pharmacological induction of HO-1 attenuates cognitive decline and neuropathological alterations [34]. Further studies would be needed to fully understand spatial and motor performance in aging $\mathrm{Hmox}_{1}{ }^{--}$and $\mathrm{Hmox}_{2}{ }^{--}$mice.

Hmox 2 null mice on a C57BL/6 $\times 129 / \mathrm{Sv}$ genetic background display an increase in body weight as well as visceral and subcutaneous fat content compared to WT animals [40-42]. In contrast, we saw 
reduced body weight particularly in female mice and no changes in the ratio of gonadal fat to body weight in Hmox $2^{--}$mice on a C57BL/6 background. This suggests that the genetic background modifies body weight and adipose phenotype in $H m o x 2^{--}$mice or that the small size of the Hmox $2^{--}$initially may lead to later obesity and metabolic dysregulation $[43,44]$. In fact, others have shown that Hmox $2^{--}$ mice develop the metabolic syndrome at 8 months of age, including obesity, insulin resistance, and hypertension [41]. However, at 4-5 months of age, we saw no changes in insulin sensitivity, glucose intolerance or energy expenditure in $\mathrm{Hmox}_{2}{ }^{-/-}$mice compared to WT littermates. This suggests that Hmox $2^{-/-}$mice develop the metabolic syndrome in an age-dependent manner, consistent with the onset of the metabolic syndrome in individuals who are small for gestational age or intrauterine growth restricted [45]. Although we did not document the weight of the pups at birth in each litter, Hmox2-mice grew faster than their WT littermates at $4-5$ months old. This may be responsible for the metabolic derangement in these knockout mice. We also did not examine blood pressure or lipid metabolism in the Hmox $1^{--}$and Hmox $2^{--}$mice at 4-5 months of age.

The UCP protein is capable of dissipating the proton gradient into mitochondrial matrix, called proton leak. The WAT does not normally exhibit uncoupled respiration or express UCP1. This agrees with high cycle threshold values observed in real-time PCR assay of UCP1 in gonadal fat pads. Elevated UCP1 protein levels are sufficient to improve glucose uptake in human white adipocytes, whereas UCP2 protein represses glycolysis in fibroblasts [46,47]. In addition, lactate can increase UCP1 and thermogenic gene expression as well as the browning of white adipocytes [48]. Nevertheless, increased proton leak and glycolysis in in gonadal fat pads of Hmox $2^{--}$mice are not associated with UCP expression. Whether increased proton leakage of WAT compensates for the abolishment of HO-2 activity in nearby tissues is unclear. HO-2 coordinates with 6-phosphofructo-2-kinase/fructose-2,6-bisphosphatase 4, a key enzyme in glycolysis, to maintain glucose homeostasis [49], however its role in our model was not explored. Ultimately, it is still unknown by which pathways Hmox 2 deletion increases glycolysis. Overall, the increased proton leak and increased glycolysis would contribute to less generation of ATP and increased heat loss, possibly explaining the lower weights in the Hmox $2^{-/-}$females.

Usually there is compensatory induction of HO-1 in the absence of HO-2, but not vice versa [50,51]. Interestingly, $\mathrm{HO}-1$ protein is decreased in $\mathrm{Hmox}_{2}{ }^{--}$adipocytes, and pharmacological induction of $\mathrm{HO}-1$ by cobalt protoporphyrin rescues adipocyte dysfunction in Hmox $2^{--}$mice [52]. We did not observe changes in Hmox 1 gene expression in Hmox $2^{--}$mice. Thus, abnormal proton leak and glycolysis in Hmox $2^{--}$mice seems not due to changes in HO-1. In contrast to the changes in the gonadal WAT, there were no changes in proton leak in the interscapular BAT of Hmox $2^{--}$mice. The discrepancies in proton leak between WAT and BAT in Hmox $2^{--}$mice remain unclear.

There are certain limitations in this study, which include an unbalanced and small sample size in certain groups. This particularly affects the analysis of statistical power for the gender subgroups.

In conclusion, reduced insulin sensitivity and physical activity were observed in $H$ mox $1^{-/}$but not in $\mathrm{Hmox}_{2}{ }^{--}$mice. There were no changes in energy expenditure, spatial and motor performance deficits, gonadal fat weight, or mitochondrial respiration of gonadal fat tissues in young adult $H m o x 1^{--}$mice. Gonadal fat weight, physical activity, and energy expenditure were not altered by Hmox2 deletion. Both proton leak and glycolysis were increased in gonadal fat tissues in young adult $\mathrm{Hmox}_{2}{ }^{-}$mice, which was not associated with changes in UCP expression.

\section{Materials and Methods}

\subsection{Mice}

Hmox $1^{--}$and Hmox $2^{--}$mice as well as their WT littermates (male and female, 4-5 months old) were used as we described previously [53,54]. Hmox $1^{-/}$mice are of a C57Bl/6 background. We crossed Hmox $2^{--}$mice (B6/129 background) with C57BL/6 mice to generate Hmox $2^{--}$mice with a C57BL/6 background for experiments. All animal experiments were reviewed and approved by the Institutional 
Animal Care and Use Committee (IACUC) of Brown University. The number of the IACUC is 1507000150, which was approved on 1 October 2015.

\subsection{Glucose Tolerance and Insulin Sensitivity Testing}

For glucose tolerance tests, mice were fasted for $16 \mathrm{~h}$. A baseline glucose reading was taken using a handheld glucose meter, followed by an intraperitoneal injection of glucose (2 g/kg) [55]. Glucose readings were taken at $15,30,45,60,90$, and 120 min post-injection. For insulin sensitivity tests, mice were fasted for $6 \mathrm{~h}$. A baseline glucose reading was taken using a handheld glucose meter, followed by an injection of insulin (1.25 U/kg for females, $2 \mathrm{U} / \mathrm{kg}$ for males, Humulin-R, Lilly) [56]. Different doses of insulin were used in male and female, as female mice are more insulin sensitive than males [57]. Glucose readings were taken at 15, 30, 45, 60, 90, and $120 \mathrm{~min}$ post insulin injection.

\subsection{Home Cage Video Monitoring}

Mice were placed in individual shoebox-style cages and allowed to acclimate to the cages for $48 \mathrm{~h}$ before monitoring began. Mice were kept on a normal light/dark cycle and provided food and water ad libitum. Mouse spontaneous activity in home cage was recorded using automated computer vision analysis (CLAMS, Oxymax Open Circuit Calorimeter, Columbus Instruments, Columbus, OH, USA) of continuous video recordings for 5 days [58]. The activity includes micromovements, sleeping/resting, consumption (eating and drinking), and active behaviors (grooming, hanging, rearing and walking). The percentage of time spent on resting and active behaviors was presented.

\subsection{Rotarod Testing}

Motor coordination in mice was tested using a rotarod instrument (MedAssociates, Inc., St. Alban, VT) as previously described [59]. In brief, mice were acclimated to the rotarod at 4 revolutions per min (RPM) for $1 \mathrm{~min}$ prior to experiments. For testing, the instrument accelerated at a constant rate from 4 to 40 RPM over $5 \mathrm{~min}$. The latency to fall off during acceleration and at maximal speed (40 RPM) was recorded digitally when the mouse fell from the rotarod and broke an infrared beam. Mice were tested three times per day on three consecutive days, and the best performance for each animal was taken.

\subsection{Measuring Indirect Calorimetry}

A Comprehensive Laboratory Animal Monitoring System (Columbus Instruments) was used to measure mouse oxygen consumption $\left(\mathrm{VO}_{2}\right), \mathrm{CO}_{2}$ production $\left(\mathrm{VCO}_{2}\right)$, and respiratory quotient as described previously $[56,60]$. Mice were placed in individual boxes with food and water provided ad libitum. Mice were allowed to acclimate to the chambers for $24 \mathrm{~h}$ before data collection began, and data was collected over a $24 \mathrm{~h}$ period. Energy expenditure was calculated using the formula $\mathrm{VO}_{2} \times\left(3.815+1.232 \times\right.$ respiratory quotient), and normalized to (body mass) ${ }^{0.75}$ [56]. Respiratory exchange ratio was calculated as a ratio of $\mathrm{VCO}_{2}$ toVO 2 .

\subsection{Evaluating Mitochondrial Respiration and Glycolysis in Whole Adipose Tissues}

Mitochondrial respiration and glycolysis were measured in adipose tissues using a Seahorse XF24 Analyzer (Agilent Technologies) as described previously [61]. In brief, we used a $3 \mathrm{~mm}$ biopsy punch to harvest a plug of tissue from gonadal (white) and interscapular (brown) fat pads. Adipose tissue $(\sim 20 \mathrm{mg})$ was placed to cover the center of the wells of the islet capture plate. Islet capture screens were applied and wells were washed twice with warm assay medium to remove fat droplets. Tissue was equilibrated for 8 baseline measurements. After the first and second injections, 5 measurements were taken, and after the final injection, 7 measurements were taken. Drug concentrations in ports were as follows: oligomycin: $100 \mu \mathrm{M}$, FCCP: $800 \mu \mathrm{M}$, rotenone: $30 \mu \mathrm{M}$, antimycin A: $120 \mu \mathrm{M}$, glucose: $200 \mathrm{mM}$, and 2-DG: $1.25 \mathrm{M}$. 


\subsection{Determining $m R N A$ Levels by $q R T-P C R$}

Total RNA was extracted by the TRIzol reagent, and purified using the RNeasy miniprep kit (Qiagen, Valencia, CA, USA). RNA samples were quantified by the NanoDrop ${ }^{\mathrm{TM}}$ One Microvolume UV-Vis Spectrophotometer (Thermo Scientific, Wilmington, DE, USA). Then, 400 nanograms of total RNA was used for reverse transcription with Taqman ${ }^{\circledR}$ Reverse Transcription Reagents (ThermoFisher Scientific). One microliter of cDNA was used for real-time PCR reactions in the 7300 Real-Time PCR System (Applied Biosystems). All Taqman gene probes were purchased from Thermo Fisher Scientific: UCP1 (Mm01244861_m1), UCP2 (Mm00627599_m1), UCP3 (Mm01163394_m1), Hmox1 (Mm00516006_m1) and Hmox2 (Mm00468922_m1). Gene expression was normalized to 18s rRNA levels. Relative RNA abundance was quantified by the comparative $2^{-\Delta \Delta C t}$ method.

\subsection{Statistical Analysis}

Statistical analyses were performed using GraphPad Prism 8 (GraphPad Software, San Diego, CA, USA). The results were expressed as mean \pm SEM. The $t$-test was used for detecting statistical significance of the differences between means of two groups after checking the normality of data. The statistical significance of the differences among groups was evaluated by using two-way ANOVA for overall significance, followed by the Tukey-Kramer test. Statistical significance was considered present when $p<0.05$.

\section{Conclusions}

HO-1 maintains insulin sensitivity, while HO-2 represses glucose metabolism and proton leak in white adipose tissues under basal condition. This suggests that HO-1 and HO-2 differentially modulate global metabolism as well as metabolism of adipose tissues.

Author Contributions: Conception and Design: A.L.P., P.A.D.; Data acquisition and analysis: H.Y., A.L.P., J.L., H.X.; Data Interpretation: H.Y., P.A.D.; Drafting the manuscript: H.Y.; Revising the manuscript: H.Y., P.A.D. All authors have read and agreed to the published version of the manuscript.

Funding: This work was supported by the Warren Alpert Foundation (to PAD), an Institutional Development Award (IDeA) from the NIGMS of NIH (grant \#P20GM103652) and the Falk Medical Research Trust Catalyst Award (to HY).

Acknowledgments: We thank Kevin Bath at the Department of Cognitive, Linguistic, and Psychological Sciences, Brown University for performing the video monitoring study.

Conflicts of Interest: The authors declare no conflict of interest. The funders had no role in the design of the study; in the collection, analyses, or interpretation of data; in the writing of the manuscript, or in the decision to publish the results.

\section{Abbreviation}

$\begin{array}{ll}\text { BAT } & \text { brown adipose tissue; } \\ \text { ECAR } & \text { extracellular acidification; } \\ \text { HO } & \text { heme oxygenase; } \\ \text { OCR } & \text { oxygen consumption rate; } \\ \text { UCP } & \text { uncoupling protein; } \\ \text { WAT } & \text { white adipose tissue; }\end{array}$

\section{References}

1. Jais, A.; Einwallner, E.; Sharif, O.; Gossens, K.; Lu, T.T.; Soyal, S.M.; Medgyesi, D.; Neureiter, D.; Paier-Pourani, J.; Dalgaard, K.; et al. Heme oxygenase-1 drives metaflammation and insulin resistance in mouse and man. Cell 2014, 158, 25-40. [CrossRef] [PubMed]

2. Liu, N.; Wang, X.; McCoubrey, W.K.; Maines, M.D. Developmentally regulated expression of two transcripts for heme oxygenase- 2 with a first exon unique to rat testis: Control by corticosterone of the oxygenase protein expression. Gene 2000, 241, 175-183. [CrossRef] 
3. Zakhary, R.; Gaine, S.P.; Dinerman, J.L.; Ruat, M.; Flavahan, N.A.; Snyder, S.H. Heme oxygenase 2: Endothelial and neuronal localization and role in endothelium-dependent relaxation. Proc. Natl. Acad. Sci. USA 1996, 93, 795-798. [CrossRef] [PubMed]

4. $\quad$ Lin, Q.S.; Weis, S.; Yang, G.; Zhuang, T.; Abate, A.; Dennery, P.A. Catalytic inactive heme oxygenase-1 protein regulates its own expression in oxidative stress. Free Radic. Biol. Med. 2008, 44, 847-855. [CrossRef] [PubMed]

5. Biswas, C.; Shah, N.; Muthu, M.; La, P.; Fernando, A.P.; Sengupta, S.; Yang, G.; Dennery, P.A. Nuclear heme oxygenase-1 (HO-1) modulates subcellular distribution and activation of Nrf2, impacting metabolic and anti-oxidant defenses. J. Biol. Chem. 2014, 289, 26882-26894. [CrossRef] [PubMed]

6. Dennery, P.A. Signaling function of heme oxygenase proteins. Antioxid. Redox Signal. 2014, 20, 1743-1753. [CrossRef]

7. Intagliata, S.; Salerno, L.; Ciaffaglione, V.; Leonardi, C.; Fallica, A.N.; Carota, G.; Amata, E.; Marrazzo, A.; Pittala, V.; Romeo, G. Heme Oxygenase-2 (HO-2) as a therapeutic target: Activators and inhibitors. Eur. J. Med. Chem. 2019, 183, 111703. [CrossRef]

8. Wagner, A.; Dallongeville, J.; Haas, B.; Ruidavets, J.B.; Amouyel, P.; Ferrieres, J.; Simon, C.; Arveiler, D. Sedentary behaviour, physical activity and dietary patterns are independently associated with the metabolic syndrome. Diabetes Metab. 2012, 38, 428-435. [CrossRef]

9. Das, M.; Pal, S.; Ghosh, A. Family history of type 2 diabetes and prevalence of metabolic syndrome in adult Asian Indians. J. Cardiovasc. Dis. Res. 2012, 3, 104-108. [CrossRef]

10. Jenko-Praznikar, Z.; Petelin, A.; Jurdana, M.; Ziberna, L. Serum bilirubin levels are lower in overweight asymptomatic middle-aged adults: An early indicator of metabolic syndrome? Metabolism 2013, 62, 976-985. [CrossRef]

11. Jehn, M.; Clark, J.M.; Guallar, E. Serum ferritin and risk of the metabolic syndrome in U.S. adults. Diabetes Care 2004, 27, 2422-2428. [CrossRef] [PubMed]

12. Braud, L.; Pini, M.; Muchova, L.; Manin, S.; Kitagishi, H.; Sawaki, D.; Czibik, G.; Ternacle, J.; Derumeaux, G.; Foresti, R.; et al. Carbon monoxide-induced metabolic switch in adipocytes improves insulin resistance in obese mice. JCI Insight 2018, 3. [CrossRef]

13. Ptilovanciv, E.O.; Fernandes, G.S.; Teixeira, L.C.; Reis, L.A.; Pessoa, E.A.; Convento, M.B.; Simoes, M.J.; Albertoni, G.A.; Schor, N.; Borges, F.T. Heme oxygenase 1 improves glucoses metabolism and kidney histological alterations in diabetic rats. Diabetol. Metab. Syndr. 2013, 5, 3. [CrossRef]

14. Ghio, A.J.; Case, M.W.; Soukup, J.M. Heme oxygenase activity increases after exercise in healthy volunteers. Free Radic. Res. 2018, 52, 267-272. [CrossRef]

15. Li, M.; Kim, D.H.; Tsenovoy, P.L.; Peterson, S.J.; Rezzani, R.; Rodella, L.F.; Aronow, W.S.; Ikehara, S.; Abraham, N.G. Treatment of obese diabetic mice with a heme oxygenase inducer reduces visceral and subcutaneous adiposity, increases adiponectin levels, and improves insulin sensitivity and glucose tolerance. Diabetes 2008, 57, 1526-1535. [CrossRef] [PubMed]

16. Hamilton, M.T.; Hamilton, D.G.; Zderic, T.W. Role of low energy expenditure and sitting in obesity, metabolic syndrome, type 2 diabetes, and cardiovascular disease. Diabetes 2007, 56, 2655-2667. [CrossRef] [PubMed]

17. Frisardi, V.; Imbimbo, B.P. Metabolic-cognitive syndrome: Metabolic approach for the management of Alzheimer's disease risk. J. Alzheimers Dis. 2012, 30 (Suppl. 2), S1-S4. [CrossRef] [PubMed]

18. Shiraishi, F.; Curtis, L.M.; Truong, L.; Poss, K.; Visner, G.A.; Madsen, K.; Nick, H.S.; Agarwal, A. Heme oxygenase-1 gene ablation or expression modulates cisplatin-induced renal tubular apoptosis. Am. J. Physiol. Renal Physiol. 2000, 278, F726-F736. [CrossRef] [PubMed]

19. Salem, G.H.; Dennis, J.U.; Krynitsky, J.; Garmendia-Cedillos, M.; Swaroop, K.; Malley, J.D.; Pajevic, S.; Abuhatzira, L.; Bustin, M.; Gillet, J.P.; et al. SCORHE: A novel and practical approach to video monitoring of laboratory mice housed in vivarium cage racks. Behav. Res. Methods 2015, 47, 235-250. [CrossRef] [PubMed]

20. Singh, S.; Bermudez-Contreras, E.; Nazari, M.; Sutherland, R.J.; Mohajerani, M.H. Low-cost solution for rodent home-cage behaviour monitoring. PLOS ONE 2019, 14, e0220751. [CrossRef]

21. Deacon, R.M. Measuring motor coordination in mice. J. Vis. Exp. 2013, e2609. [CrossRef] [PubMed]

22. Zhang, Y.; Fischer, K.E.; Soto, V.; Liu, Y.; Sosnowska, D.; Richardson, A.; Salmon, A.B. Obesity-induced oxidative stress, accelerated functional decline with age and increased mortality in mice. Arch. Biochem. Biophys. 2015, 576, 39-48. [CrossRef] [PubMed] 
23. Chang, E.F.; Wong, R.J.; Vreman, H.J.; Igarashi, T.; Galo, E.; Sharp, F.R.; Stevenson, D.K.; Noble-Haeusslein, L.J. Heme oxygenase- 2 protects against lipid peroxidation-mediated cell loss and impaired motor recovery after traumatic brain injury. J. Neurosci. 2003, 23, 3689-3696. [CrossRef] [PubMed]

24. Soares, M.J.; Cummings, N.K.; Ping-Delfos, W.L. Energy metabolism and the metabolic syndrome: Does a lower basal metabolic rate signal recovery following weight loss? Diabetes. Metab. Syndr. 2011, 5, 98-101. [CrossRef] [PubMed]

25. Ekelund, U.; Brage, S.; Franks, P.W.; Hennings, S.; Emms, S.; Wareham, N.J. Physical activity energy expenditure predicts progression toward the metabolic syndrome independently of aerobic fitness in middle-aged healthy Caucasians: The Medical Research Council Ely Study. Diabetes Care 2005, 28, 1195-1200. [CrossRef]

26. Longo, M.; Zatterale, F.; Naderi, J.; Parrillo, L.; Formisano, P.; Raciti, G.A.; Beguinot, F.; Miele, C. Adipose Tissue Dysfunction as Determinant of Obesity-Associated Metabolic Complications. Int. J. Mol. Sci 2019, 20, 2358. [CrossRef]

27. Chusyd, D.E.; Wang, D.; Huffman, D.M.; Nagy, T.R. Relationships between Rodent White Adipose Fat Pads and Human White Adipose Fat Depots. Front. Nutr. 2016, 3, 10. [CrossRef]

28. Steel, J.H.; White, R.; Parker, M.G. Role of the RIP140 corepressor in ovulation and adipose biology. J. Endocrinol. 2005, 185, 1-9. [CrossRef]

29. Goodman, A.I.; Chander, P.N.; Rezzani, R.; Schwartzman, M.L.; Regan, R.F.; Rodella, L.; Turkseven, S.; Lianos, E.A.; Dennery, P.A.; Abraham, N.G. Heme oxygenase-2 deficiency contributes to diabetes-mediated increase in superoxide anion and renal dysfunction. J. Am. Soc. Nephrol. 2006, 17, 1073-1081. [CrossRef]

30. Burgess, A.; Li, M.; Vanella, L.; Kim, D.H.; Rezzani, R.; Rodella, L.; Sodhi, K.; Canestraro, M.; Martasek, P.; Peterson, S.J.; et al. Adipocyte heme oxygenase-1 induction attenuates metabolic syndrome in both male and female obese mice. Hypertension 2010, 56, 1124-1130. [CrossRef]

31. Shakeri-Manesch, S.; Zeyda, M.; Huber, J.; Ludvik, B.; Prager, G.; Stulnig, T.M. Diminished upregulation of visceral adipose heme oxygenase-1 correlates with waist-to-hip ratio and insulin resistance. Int. J. Obes. Lond. 2009, 33, 1257-1264. [CrossRef] [PubMed]

32. Singh, S.P.; Grant, I.; Meissner, A.; Kappas, A.; Abraham, N.G. Ablation of adipose-HO-1 expression increases white fat over beige fat through inhibition of mitochondrial fusion and of PGC1alpha in female mice. Horm. Mol. Biol. Clin. Investig. 2017, 31. [CrossRef]

33. Huang, J.Y.; Chiang, M.T.; Chau, L.Y. Adipose overexpression of heme oxygenase-1 does not protect against high fat diet-induced insulin resistance in mice. PLoS ONE 2013, 8, e55369. [CrossRef] [PubMed]

34. Kurucz, A.; Bombicz, M.; Kiss, R.; Priksz, D.; Varga, B.; Hortobagyi, T.; Trencsenyi, G.; Szabo, R.; Posa, A.; Gesztelyi, R.; et al. Heme Oxygenase-1 Activity as a Correlate to Exercise-Mediated Amelioration of Cognitive Decline and Neuropathological Alterations in an Aging Rat Model of Dementia. Biomed. Res. Int. 2018, 2018, 7212861. [CrossRef] [PubMed]

35. Bird, S.R.; Hawley, J.A. Update on the effects of physical activity on insulin sensitivity in humans. BMJ Open Sport Exerc. Med. 2016, 2, e000143. [CrossRef]

36. Liao, W.; Yang, W.; Pan, Q.; Shen, Z.; Ai, W.; Guo, S. Heme Oxygenase-1 Promotes Hepatic Glucose Production via Increasing the Intracellular Ferrous Iron. Diabetes 2020, 69, 1718. [CrossRef]

37. Jung, T.W.; Kim, H.C.; Abd El-Aty, A.M.; Jeong, J.H. Protectin DX suppresses hepatic gluconeogenesis through AMPK-HO-1-mediated inhibition of ER stress. Cell Signal. 2017, 34, 133-140. [CrossRef]

38. Schipper, H.M. Biomarker potential of heme oxygenase-1 in Alzheimer's disease and mild cognitive impairment. Biomark Med. 2007, 1, 375-385. [CrossRef]

39. Wang, D.; Hui, Y.; Peng, Y.; Tang, L.; Jin, J.; He, R.; Li, Y.; Zhang, S.; Li, L.; Zhou, Y.; et al. Overexpression of heme oxygenase 1 causes cognitive decline and affects pathways for tauopathy in mice. J. Alzheimers Dis. 2015, 43, 519-534. [CrossRef]

40. Vanella, L.; Li Volti, G.; Guccione, S.; Rappazzo, G.; Salvo, E.; Pappalardo, M.; Forte, S.; Schwartzman, M.L.; Abraham, N.G. Heme oxygenase-2/adiponectin protein-protein interaction in metabolic syndrome. Biochem. Biophys. Res. Commun. 2013, 432, 606-611. [CrossRef] 
41. Sodhi, K.; Inoue, K.; Gotlinger, K.H.; Canestraro, M.; Vanella, L.; Kim, D.H.; Manthati, V.L.; Koduru, S.R.; Falck, J.R.; Schwartzman, M.L.; et al. Epoxyeicosatrienoic acid agonist rescues the metabolic syndrome phenotype of HO-2-null mice. J. Pharmacol. Exp. Ther. 2009, 331, 906-916. [CrossRef] [PubMed]

42. Cao, J.; Puri, N.; Sodhi, K.; Bellner, L.; Abraham, N.G.; Kappas, A. Apo A1 Mimetic Rescues the Diabetic Phenotype of HO-2 Knockout Mice via an Increase in HO-1 Adiponectin and LKBI Signaling Pathway. Int. J. Hypertens. 2012, 2012, 628147. [CrossRef] [PubMed]

43. Kanaka-Gantenbein, C. Fetal origins of adult diabetes. Ann. N. Y. Acad. Sci. 2010, 1205, 99-105. [CrossRef] [PubMed]

44. Barker, D.J. The fetal and infant origins of adult disease. BMJ 1990, 301, 1111. [CrossRef]

45. Kaijser, M.; Bonamy, A.K.; Akre, O.; Cnattingius, S.; Granath, F.; Norman, M.; Ekbom, A. Perinatal risk factors for diabetes in later life. Diabetes 2009, 58, 523-526. [CrossRef]

46. Tews, D.; Pula, T.; Funcke, J.B.; Jastroch, M.; Keuper, M.; Debatin, K.M.; Wabitsch, M.; Fischer-Posovszky, P. Elevated UCP1 levels are sufficient to improve glucose uptake in human white adipocytes. Redox Biol. 2019, 26, 101286. [CrossRef]

47. Pecqueur, C.; Bui, T.; Gelly, C.; Hauchard, J.; Barbot, C.; Bouillaud, F.; Ricquier, D.; Miroux, B.; Thompson, C.B. Uncoupling protein-2 controls proliferation by promoting fatty acid oxidation and limiting glycolysis-derived pyruvate utilization. FASEB J. 2008, 22, 9-18. [CrossRef]

48. Carriere, A.; Jeanson, Y.; Berger-Muller, S.; Andre, M.; Chenouard, V.; Arnaud, E.; Barreau, C.; Walther, R.; Galinier, A.; Wdziekonski, B.; et al. Browning of white adipose cells by intermediate metabolites: An adaptive mechanism to alleviate redox pressure. Diabetes 2014, 63, 3253-3265. [CrossRef]

49. Li, B.; Takeda, K.; Ishikawa, K.; Yoshizawa, M.; Sato, M.; Shibahara, S.; Furuyama, K. Coordinated expression of 6-phosphofructo-2-kinase/fructose-2,6-bisphosphatase 4 and heme oxygenase 2: Evidence for a regulatory link between glycolysis and heme catabolism. Tohoku J. Exp. Med. 2012, 228, 27-41. [CrossRef]

50. Flagge, M.; Tatarov, A.; Yang, G.; Weng, Y.; Dennery, P.A. Effect of Tin Mesoporphyrin on Lung Oxidative Injury in Neonatal Mice with Absence of Heme Oxygenase-2. Pediatr. Res. 1999, 45, 196. [CrossRef]

51. Kapturczak, M.H.; Wasserfall, C.; Brusko, T.; Campbell-Thompson, M.; Ellis, T.M.; Atkinson, M.A.; Agarwal, A. Heme oxygenase-1 modulates early inflammatory responses: Evidence from the heme oxygenase-1-deficient mouse. Am. J. Pathol. 2004, 165, 1045-1053. [CrossRef]

52. Burgess, A.P.; Vanella, L.; Bellner, L.; Gotlinger, K.; Falck, J.R.; Abraham, N.G.; Schwartzman, M.L.; Kappas, A. Heme oxygenase (HO-1) rescue of adipocyte dysfunction in HO-2 deficient mice via recruitment of epoxyeicosatrienoic acids (EETs) and adiponectin. Cell Physiol. Biochem. 2012, 29, 99-110. [CrossRef [PubMed]

53. Dennery, P.A.; Spitz, D.R.; Yang, G.; Tatarov, A.; Lee, C.S.; Shegog, M.L.; Poss, K.D. Oxygen toxicity and iron accumulation in the lungs of mice lacking heme oxygenase-2. J. Clin. Investig. 1998, 101, 1001-1011. [CrossRef] [PubMed]

54. Yang, G.; Biswasa, C.; Lin, Q.S.; La, P.; Namba, F.; Zhuang, T.; Muthu, M.; Dennery, P.A. Heme oxygenase-1 regulates postnatal lung repair after hyperoxia: Role of beta-catenin/hnRNPK signaling. Redox Biol. 2013, 1, 234-243. [CrossRef]

55. Andrikopoulos, S.; Blair, A.R.; Deluca, N.; Fam, B.C.; Proietto, J. Evaluating the glucose tolerance test in mice. Am. J. Physiol. Endocrinol. Metab. 2008, 295, E1323-E1332. [CrossRef] [PubMed]

56. Li, J.; Feng, B.; Nie, Y.; Jiao, P.; Lin, X.; Huang, M.; An, R.; He, Q.; Zhou, H.E.; Salomon, A.; et al. Sucrose Nonfermenting-Related Kinase Regulates Both Adipose Inflammation and Energy Homeostasis in Mice and Humans. Diabetes 2018, 67, 400-411. [CrossRef]

57. Macotela, Y.; Boucher, J.; Tran, T.T.; Kahn, C.R. Sex and depot differences in adipocyte insulin sensitivity and glucose metabolism. Diabetes 2009, 58, 803-812. [CrossRef]

58. Hofmann, J.W.; Zhao, X.; De Cecco, M.; Peterson, A.L.; Pagliaroli, L.; Manivannan, J.; Hubbard, G.B.; Ikeno, Y.; Zhang, Y.; Feng, B.; et al. Reduced expression of MYC increases longevity and enhances healthspan. Cell 2015, 160, 477-488. [CrossRef]

59. Bath, K.G.; Pimentel, T. Effect of early postnatal exposure to valproate on neurobehavioral development and regional BDNF expression in two strains of mice. Epilepsy. Behav. 2017, 70, 110-117. [CrossRef] 
60. Nie, Y.; Gavin, T.P.; Kuang, S. Measurement of Resting Energy Metabolism in Mice Using Oxymax Open Circuit Indirect Calorimeter. Bio. Protoc. 2015, 5. [CrossRef]

61. Dunham-Snary, K.J.; Sandel, M.W.; Westbrook, D.G.; Ballinger, S.W. A method for assessing mitochondrial bioenergetics in whole white adipose tissues. Redox Biol. 2014, 2, 656-660. [CrossRef] [PubMed]

(C) 2020 by the authors. Licensee MDPI, Basel, Switzerland. This article is an open access article distributed under the terms and conditions of the Creative Commons Attribution (CC BY) license (http://creativecommons.org/licenses/by/4.0/). 